\title{
Energy potential of the modified excess sludge
}

\author{
Iwona Zawieja ${ }^{1, *}$ \\ ${ }^{1}$ Czestochowa University of Technology, Faculty of Infrastructure and Environment, Institute of \\ Environmental Engineering, ul. Brzeznicka 60a, 42-200 Czestochowa, Poland
}

\begin{abstract}
On the basis of the SCOD value of excess sludge it is possible to estimate an amount of energy potentially obtained during the methane fermentation process. Based on a literature review, it has been estimated that from $1 \mathrm{~kg}$ of SCOD it is possible to obtain $3.48 \mathrm{kWh}$ of energy. Taking into account the above methane and energy ratio (i.e. $10 \mathrm{kWh} / 1 \mathrm{Nm}^{3} \mathrm{CH}_{4}$ ), it is possible to determine the volume of methane obtained from the tested sludge. Determination of potential energy of sludge is necessary for the use of biogas as a source of power generators as cogeneration and ensure the stability of this type of system. Therefore, the aim of the study was to determine the energy potential of excess sludge subjected to the thermal and chemical disintegration. In the case of thermal disintegration, test was conducted in the low temperature $80^{\circ} \mathrm{C}$. The reagent used for the chemical modification was a peracetic acid, which in an aqueous medium having strong oxidizing properties. The time of chemical modification was 6 hours. Applied dose of the reagent was $1.0 \mathrm{ml}$ $\mathrm{CH}_{3} \mathrm{COOOH} / \mathrm{L}$ of sludge. By subjecting the sludge disintegration by the test methods achieved an increase in the SCOD value of modified sludge, indicating the improvement of biodegradability along with a concomitant increase in their energy potential. The obtained experimental production of biogas from disintegrated sludge confirmed that it is possible to estimate potential intensity of its production. The SCOD value of $2576 \mathrm{mg} \mathrm{O} / \mathrm{L}$, in the case of chemical disintegration, was obtained for a dose of $1.0 \mathrm{ml}$ $\mathrm{CH}_{3} \mathrm{COOH} / \mathrm{L}$. For this dose the $\mathrm{pH}$ value was equal 6.85. In the case of thermal disintegration maximum SCOD value was $2246 \mathrm{mg} \mathrm{O} / \mathrm{L}$ obtained at $80{ }^{\circ} \mathrm{C}$ and the time of preparation $6 \mathrm{~h}$. It was estimated that in case of thermal disintegration as well as for the chemical disintegration for selected parameters, the potential energy for model digester of active volume of $5 \mathrm{~L}$ was, respectively, 0.193 and $0,118 \mathrm{kWh}$.
\end{abstract}

\section{Introduction}

The costs of construction and operation of wastewater treatment plants are very high, therefore economic conditions force the facility operators to treat sludge as a raw material with a certain amount of fertilizer, especially energy, which may give rise to a partial return of financial expenditures. Sewage sludge, as far as possible, can be used for: agricultural purposes, as fertilizer for soils, recultivation of degraded land and landless or thermally

\footnotetext{
*Corresponding author: izawieja@poczta.onet.pl
} 
degraded land, i.e. by incineration or co-incineration of sludge with other fuels. Selection of the disintegration method should be preceded by a technical and economic analysis that takes into account the desired disintegration effect, the efficiency of the installation, the operating costs of the disintegration plant, the balance of costs associated with the operation and processing of the sludge $[1,2]$.

In the case of the disposal of sludge, it is technically and economically justified to use an anaerobic sludge stabilization process, where the energy input is mainly related to the need for optimum process temperature achievement. The demand for heat energy is proportional to the amount of sludge fed. Based on research conducted by Muhammad [3], it was found that as a result of disintegration of sludge, an increase in biogas production was achieved by $36 \%$ compared to no use of initial disintegration. There was also a decrease in the volume of sludge, which directly affects the reduction in the cost of purchasing the polymer used for the dewatering process. Pre-treatment through disintegration involves additional costs for the installation and energy consumption of the process. It is difficult to compare all disintegration methods in the economic terms, taking into account the costs and benefits of the lack of data, as most pre-treatment techniques are carried out only on a laboratory scale. It is also difficult to decide which method is more economical and effective, because each has advantages and disadvantages. The main disadvantage of mechanical methods is high energy consumption, which increases the cost of sewage sludge disintegration, while the disadvantage of chemical disintegration methods is the secondary sludge contamination by the addition of chemical reagents and the supplementary cost of their purchase.

It should be noted, however, that pre-treatment increases the amount of biogas that can be used in the cogeneration process for heat and power generation, which depreciates some of the costs incurred for the disintegration of sludge [4].

According to Dhar et al. [5] all thermal methods in the range of $50-90^{\circ} \mathrm{C}$, net savings of \$44-66 per tonne of total solids (TS). The use of disintegration of sewage sludge allows to reduce the cost of wastewater treatment by as much as $50 \%$. [6].

The aim of the study was to determine the energy potential of excess sludge subjected to the thermal and chemical disintegration using an oxidizing agent i.e.: peracetic acid.

\section{Methodology}

According to the intended purpose of the study, excess sludge was subjected anaerobic stabilization assisted by disintegration. In order to initiate the anaerobic stabilization process, a fermented sludge was used. The sludge samples were collected from a sewage treatment plant with a capacity of $90,000 \mathrm{~m}^{3} / \mathrm{d}, 314835 \mathrm{RLM}$. It is a mechanical and biological treatment plant with increased nutrients removal. Table 1 shows the physico-chemical characteristics of the sludge used in the studies.

Table 1. Selected physico-chemical indicators of excess sludge, which is the basic substrate for the study.

\begin{tabular}{|c|c|}
\hline Indicators & Excess sludge \\
\hline Volatile Suspened Solids (VSS) & $8.8 \pm 0.15 \mathrm{~g} / \mathrm{L}$ \\
\hline $\begin{array}{c}\text { Soluble Chemical Oxygen } \\
\text { Demand (SCOD) }\end{array}$ & $157 \pm 12 \mathrm{mg} \mathrm{O} / \mathrm{L}$ \\
\hline Volatile Fatty Acids (VFAs) & $72 \pm 3 \mathrm{mg} \mathrm{CH} \mathrm{COOH}_{3} / \mathrm{L}$ \\
\hline Alkalinity & $860 \pm 20 \mathrm{mg} \mathrm{CaCO}_{3} / \mathrm{L}$ \\
\hline pH & $7.2 \pm 0.2$ \\
\hline
\end{tabular}


An anaerobic stabilization process of excess sludge was carried out in a fermentation chamber made in the form of a glass cylinder with an active volume of $5 \mathrm{~L}$. The test plant consists of a biogas installation, a device providing the optimum mixing speed and keeps the constant temperature of process. The process was carried out at mesophilic temperature of $37^{\circ} \mathrm{C}$ for 25 days. Anaerobic stabilization was applied to the following sludge: - Sludge 1 - unconditioned excess sludge;

- Sludge 2 - excess sludge thermally disintegrated at $80^{\circ} \mathrm{C}$ for $6 \mathrm{~h}$;

- Sludge 3 - excess sludge chemically disintegrated using an acidic reagent $1.0 \mathrm{ml}$ of STERIDIAL/L of sludge.

Excessive sediments have been subjected to the following characteristics by performing physicochemical determinations, i.e.:

- ODM (Organic Dry Matter) according to PN-EN-12879,

- pH using a pH meter from Cole Palmer 59002-00 according to PN-9/C-04540/05, - Soluble chemical oxygen demand (SCOD) by dichromate method using HACH 2I00N IS spectrophotometer tests according to ISO 7027 in the supernatant of sludge.

- volatile fatty acids (VFAs) by steam distillation in accordance with PN-75 / C-04616/04.

- alkalinity according to PN-91 / C-04540/05.

The process of thermal disintegration of excess sludge was carried out in the low temperature i.e. $80^{\circ} \mathrm{C}$ for $6 \mathrm{~h}$. In order to perform a thermal modification excess sludge was placed in laboratory flasks with an active volume of $0.5 \mathrm{~L}$, protected from air by a glass stopper with a manometric tube. Flasks were placed in a shaking water bath. Steridial W-15, which is the aqueous solution of peracetic acid (15\%), acetic acid $(>36 \%)$ and hydrogen peroxide (18-22\%), was used during chemical disintegration. The following dose of reagent was used: $1.0 \mathrm{ml}$ of STERIDIAL/ $1 \mathrm{~L}$ of sludge. The time of the excess sludge chemical exposition was equal $6 \mathrm{~h}$. In the case of chemical disintegration, excess sludge was placed in laboratory flasks with an active volume of $0.5 \mathrm{~L}$, protected from air by a glass stopper with a manometric tube and placed in a shaker. The recorded $\mathrm{pH}$ of the sludge was corrected chemically to the proper $\mathrm{pH}$ of the methane fermentation process. It has been assumed that peracetic acid in aqueous medium is completely decomposed to acetic acid. The value of SCOD of chemically pretreatment sludge by peracetic acid should be estimated according to the following relationship $1.07 \mathrm{kgO}_{2} / \mathrm{kgCH}_{3} \mathrm{COOH}$ [7]. The percentage of peracetic acid and acetic acid in the Steridial W-15 solution and their density were taken into account.

\section{Results}

\subsection{Effect of the disintegration process conditions on the sludge physicochemical characteristics}

The studies have shown the positive effect of thermal and chemical disintegration on the increase of dissolved organic matter, which was directly reflected in the increase of SCOD value. The selection of the most favorable disintegration conditions was made on the basis of preliminary results. The increase of the volatile fatty acids concentration determined in the thermally modified excess sludge was correlated with the obtained SCOD value. In samples of modified sludge $\left(80^{\circ} \mathrm{C}\right.$ and $\left.6 \mathrm{~h}\right)$ a value of $\mathrm{O}_{2} / \mathrm{L}$ demand was equal $2246 \mathrm{mg} / \mathrm{L}$.A significant growth of the VFAs concentration was obtained in comparison to the initial value of this indicator. The VFAs concentration after the thermal disintegration process was $552 \mathrm{mg} \mathrm{CH} \mathrm{CH}_{3} \mathrm{COOH} / \mathrm{L}$. Supporting effects on the degree of hydrolysis of sludge were also reported in the case of chemical disintegrated by peracetic acid at the dose of reagent $1.0 \mathrm{ml} \mathrm{CH}{ }_{3} \mathrm{COOOH} / \mathrm{L}$ of sludge. SCOD values and VFAs concentration of $2576 \mathrm{mgO}_{2} / \mathrm{L}$ and $387 \mathrm{mgCH}_{3} \mathrm{COOH} / \mathrm{L}$ respectively were obtained. In addition, the $\mathrm{pH}$ 
value equal 6.85 of chemically sludge did not need to be adjusted to an optimum value for the further stage of the methane fermentation process.

\subsection{Generation of biogas from excess sludge subjected to 25 -day methane fermentation}

In the methane fermentation process of untreated excess sludge, about $39 \%$ digested degree was obtained. As a result of anaerobic stabilization of untreated excess sludge, SCOD and VFAs concentration of $287 \mathrm{mg} \mathrm{O}_{2} / \mathrm{L}$ and $164 \mathrm{mg} \mathrm{CH} 3 \mathrm{COOH} / \mathrm{L}$ were obtained at 25 day of treatment. At the time of initiation of the process, the values of the tested indicators were $157 \mathrm{mg} \mathrm{O} / \mathrm{L}$ and $103 \mathrm{mg} \mathrm{CH} \mathrm{COOH}_{3} \mathrm{~L}$, respectively. The $\mathrm{pH}$ on the day of initiating the process (day 0) was 7.62, while in the final day 7.43. Initial and final values of alkalinity were $880 \mathrm{mg} \mathrm{CaCO} 3 / \mathrm{L}$ and $1620 \mathrm{CaCO}_{3} / \mathrm{L}$, respectively. During the methane fermentation of non-disintegrated sludge, the highest daily biogas production value of $0.61 \mathrm{~L}$ was observed in the 13th day of the process, recording approximately $82 \%$ of the methane fraction. Total production and biogas yield of $4.3 \mathrm{~L}$ and $0.158 \mathrm{~L} / \mathrm{g}$ VSS was obtained. The biogas energy potential of an average volume content of about $80 \%$ methane generated from a 5L of active reactor was estimated to be about $0.0344 \mathrm{kWh}$. Table 2 presents selected physicochemical indicators of untreated excess sludge during methane fermentation (25 days), while Figure 1 shows the daily production of biogas with volume of methane.

Table 2. Selected physico-chemical indicators obtained for Sludge1 subjected to 25-day methane fermentation.

\begin{tabular}{|c|c|c|}
\hline \multirow[t]{2}{*}{ Indicator/Unit } & \multicolumn{2}{|c|}{$\begin{array}{l}\text { The methane fermentation } \\
\text { time }\end{array}$} \\
\hline & Od & 25d \\
\hline Volatile Suspened Solids (VSS), g/L & $\mathbf{8 . 8} \pm 0.15$ & $\mathbf{5 . 4} \pm 0.14$ \\
\hline Alkalinity, mg CaCO $3 / \mathrm{L}$ & $\mathbf{8 8 0} \pm 40$ & $1620 \pm 20$ \\
\hline $\begin{array}{c}\text { Chemical Oxygen Demand (SCOD), } \\
\mathrm{mg} \mathrm{O}_{2} / \mathrm{L}\end{array}$ & $157 \pm 8$ & $\mathbf{2 8 7} \pm 12$ \\
\hline $\begin{array}{l}\text { Volatile Fatty Acids, } \\
\mathrm{mgCH}_{3} \mathrm{COOH} / \mathrm{L}\end{array}$ & $\mathbf{1 0 3} \pm 12$ & $\mathbf{1 6 4} \pm 15$ \\
\hline pH & $\mathbf{7 . 5 6} \pm 0.21$ & $7.41 \pm 0.16$ \\
\hline
\end{tabular}

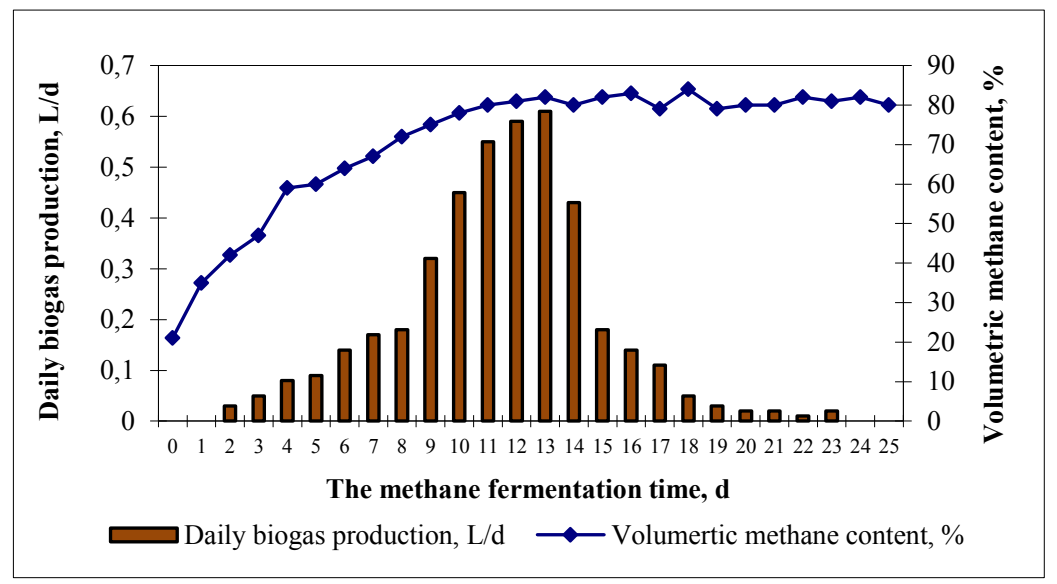

Fig. 1. Daily biogas production with respect to volume of methane during anaerobic stabilization of untreated excess sludge (Sludge 1). 


\subsection{Generation of biogas from thermally disintegrated excess sludge subjected to 25-day methane fermentation}

Methane fermentation of thermally modified excess sludge at temperature $80^{\circ} \mathrm{C}$ and time $6 \mathrm{~h}$ (Sludge 2), resulted with $71 \%$ degree of sludge digestion. At 25 th day the SCOD and VFAs concentrations were $357 \mathrm{mg} \mathrm{O} / 2$ and $241 \mathrm{mg} \mathrm{CH}_{3} \mathrm{COOH} / \mathrm{L}$, respectively, while at the first day of the process parameters were equal $2246 \mathrm{mg} \mathrm{O}_{2} / \mathrm{L}$ and $552 \mathrm{mg} \mathrm{CH}_{3} \mathrm{COOH} / \mathrm{L}$, respectively. The $\mathrm{pH}$ during the initiation day was 7.18 , the final day was 7.38 , and the initial and final alkalinity values were $660 \mathrm{mg} \mathrm{CaCO} / / \mathrm{L}$ and $2860 \mathrm{CaCO}_{3} / \mathrm{L}$, respectively. The highest daily biogas production value of $1.87 \mathrm{~L}$ was observed in the 8 th day of the process, recording about $83 \%$ methane content. A total biogas production of $15.46 \mathrm{~L}$ and a biogas yield of $0.493 \mathrm{~L} / \mathrm{g}$ VSS were obtained. The biogas energy potential of an average content of about $80 \%$ methane generated from a $5 \mathrm{~L}$ of active reactor was estimated to be about $0.193 \mathrm{kWh}$. Table 3 shows the physicochemical indicators of thermally pretreated sludge, during the 25-day methane fermentation process, while Figure 2 shows the daily production of biogas with the volume of methane.

Table 3. Selected physico-chemical indicators obtained for Sludge 2 subjected to 25 -day methane fermentation.

\begin{tabular}{|c|c|c|}
\hline \multirow{2}{*}{ Indicator/Unit } & \multicolumn{2}{|c|}{$\begin{array}{c}\text { The methane fermentation } \\
\text { time }\end{array}$} \\
\hline & Od & 25d \\
\hline Volatile Suspened Solids (VSS), g/L & $\mathbf{8 . 8} \pm 0.15$ & $\mathbf{2 . 5 3} \pm 0.18$ \\
\hline Alkalinity, $\mathrm{mg} \mathrm{CaCO}_{3} / \mathrm{L}$ & $660 \pm 20$ & $\mathbf{2 8 6 0} \pm 20$ \\
\hline $\begin{array}{c}\text { Soluble Chemical Oxygen Demand } \\
\text { (SCOD), } \mathrm{mg} \mathrm{O}_{2} / \mathrm{L}\end{array}$ & $\mathbf{2 2 4 6} \pm 32$ & $\mathbf{3 5 7} \pm 16$ \\
\hline $\begin{array}{l}\text { Volatile Fatty Acids, } \\
\mathrm{mgCH}_{3} \mathrm{COOH} / \mathrm{L}\end{array}$ & $\mathbf{5 5 2} \pm 11$ & $241 \pm 6$ \\
\hline pH & $\mathbf{7 . 1 8} \pm 0.22$ & $\mathbf{7 . 3 8} \pm 0.17$ \\
\hline
\end{tabular}

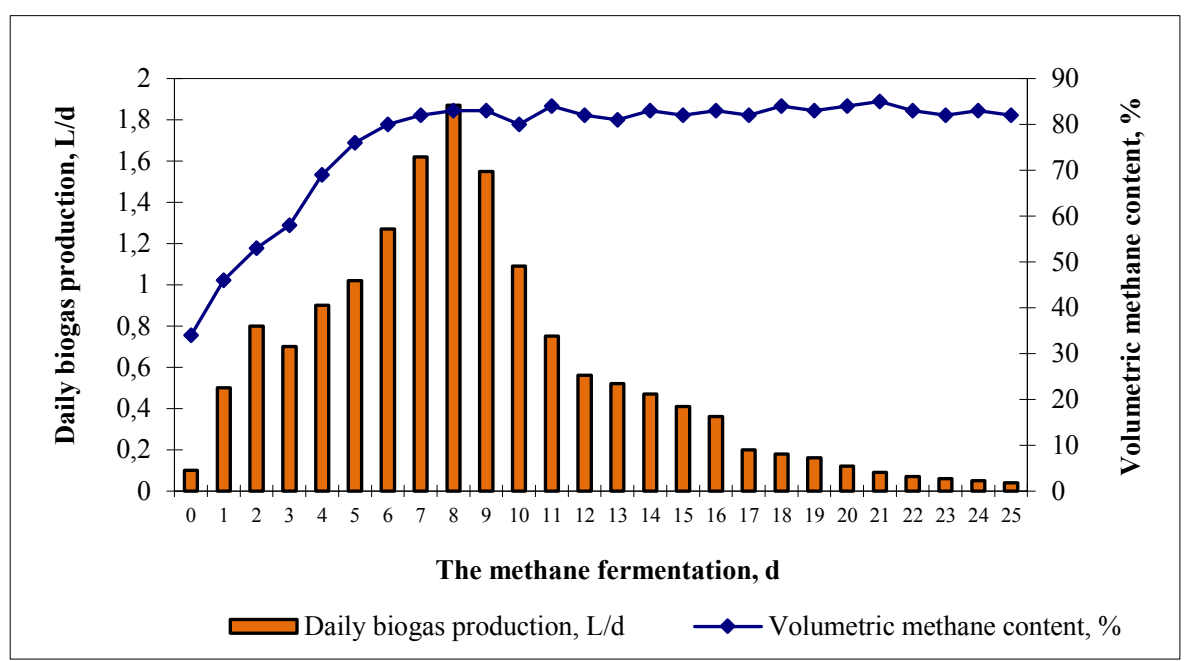

Fig. 2. Daily biogas production with respect to volume of methane during anaerobic stabilization of thermally modified excess sludge (Sludge 2). 


\subsection{Generation of biogas from chemically disintegrated excess sludge subjected to 25-day methane fermentation}

In the next study cycle, excess sludge was chemically modified using the selected dose of reagent, i.e.: $1.0 \mathrm{ml}$ of STERIDIAL/L of sludge (Sludge 3). The $53 \%$ digested degree was obtained in the stabilization process of the chemically modified sludge. The SCOD value of $746 \mathrm{mg} \mathrm{O}_{2} / \mathrm{L}$ and the concentration of volatile fatty acids (VSAs) of $543 \mathrm{mg} \mathrm{CH}_{3} \mathrm{COOH} / \mathrm{L}$ were obtained during the 25 day conducting of the process. However, during the initiation of the process $(0 \mathrm{~d})$ the SCOD and VFAs concentration were $886 \mathrm{mg} \mathrm{O} / \mathrm{L}$ and $487 \mathrm{mg} \mathrm{CH} \mathrm{CHOH}_{3} \mathrm{CO}$. The $\mathrm{pH}$ during the day of initiation of the process (day 0 ) was 7.38 , in the final day $\mathrm{pH}$ value was 7.42 , while the initial and final alkalinity value were equal respectively 650 and $2560 \mathrm{CaCO}_{3} / \mathrm{L}$. At the seventh day of methane fermentation of chemically disintegrated excess sludge, the highest daily biogas production was observed: $1.63 \mathrm{~L}$ with $85 \%$ volumetric methane content. Total biogas production of $14.75 \mathrm{~L}$ and a biogas yield of $0.625 \mathrm{~L} / \mathrm{g}$ VSS was observed. It was estimated that the biogas energy potential of an average of about $80 \%$ methane generated from a $5 \mathrm{~L}$ of active reactor was about $0.118 \mathrm{kWh}$. Table 4 presents selected physicochemical indicators of chemically modified excess sludge during the 25-day methane fermentation, while Figure 1 shows the daily production of biogas with volume of methane.

Table 4. Selected physico-chemical indicators obtained for Sludge 3 subjected to 25-day methane fermentation.

\begin{tabular}{|c|c|c|}
\hline \multirow{2}{*}{ Indicator/Unit } & \multicolumn{2}{|c|}{ The methane fermentation } \\
time \\
\cline { 2 - 3 } & $\mathbf{0 d}$ & $\mathbf{2 5 d}$ \\
\hline Volatile Suspened Solids (VSS) & $\mathbf{8 . 8} \pm 0.15$ & $\mathbf{4 . 0 8} \pm 0.14$ \\
\hline Alkalinity, $\mathbf{m g} \mathbf{C a C O}_{3} / \mathbf{L}$ & $\mathbf{7 6 0} \pm 20$ & $\mathbf{2 6 8 0} \pm 40$ \\
\hline $\begin{array}{c}\text { Soluble Chemical Oxygen Demand } \\
\text { (SCOD), } \mathbf{m g} \mathbf{O}_{2} / \mathbf{L}\end{array}$ & $\mathbf{2 5 7 5} \pm 46$ & $\mathbf{8 5 1} \pm 23$ \\
\hline Volatile Fatty Acids, $\mathbf{m g C H} \mathbf{C O O H} / \mathbf{L}$ & $\mathbf{3 8 7} \pm 9$ & $\mathbf{4 7 8} \pm 12$ \\
\hline $\mathbf{p H}$ & $\mathbf{6 . 8 5} \pm 0.25$ & $\mathbf{7 . 3 7} \pm 0.18$ \\
\hline
\end{tabular}




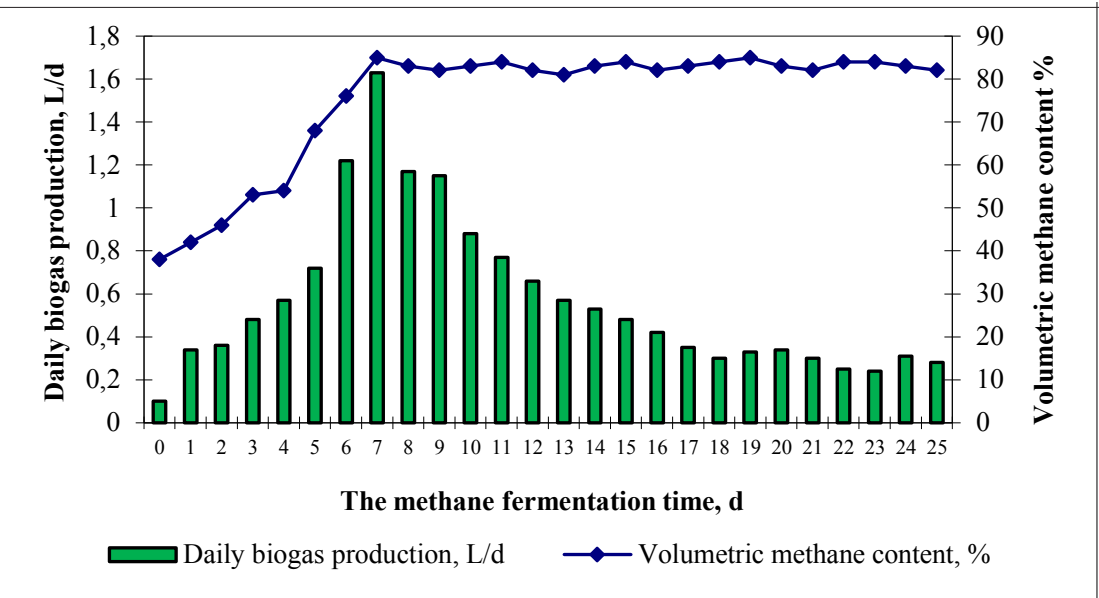

Fig. 3. Daily biogas production with respect to volume of methane during anaerobic stabilization of chemically modified excess sludge (Sludge 3).

Yield of biogas production, and degree of sludge digestion, obtained during 25-day anaerobic stabilization of chemically modified excess sludge, shows a significant increase of susceptibility of modified excess sludge to biodegradation, in comparison to untreated sludge. A significant increase of the energy potential of disintegrated excess sludge, with respect to the untreated sludge was also observed.

\section{Conclusions}

Since, the stabilization process is spontaneous and the limiting phase is the hydrolysis phase, it is desirable to subject the excess sludge to disintegration processes that affects the increase of energy efficiency of the process.

Based on the results of the research, the following conclusions were made: 1. The application of selected methods of disintegration of excess sludge prior to the anaerobic stabilization process resulted in an increase in process efficiency expressed as an increase in the unit value of biogas production.

2. The application of the studied disintegration methods, in the technological process of sludge treatment, entails both the ecological and economic benefits of the reduced environmental burden through the use of sludge modification methods that do not cause additional pollution of the environment.

3. As a result of methane fermentation of excess sludge modified by thermal disintegration at $80^{\circ} \mathrm{C}$ and chemical disintegration using the reagent dose of $1.0 \mathrm{ml}$ of STERIDIAL/L of sludge, the biogas yield value was 0.493 and $0.625 \mathrm{~L} / \mathrm{gVSS}$, and digested degree about $71 \%$ and $53 \%$ respectively. It was found that the biogas energy potential about $80 \%$ of the volume methane content, which was generated from a $5 \mathrm{~L}$ reactor volume, was 0.193 and $0.118 \mathrm{kWh}$ respectively, for the thermal and chemically disintegrated sludge.

The research was funded under the project No. BS - PB-401/303/12.

\section{References}

1. G. Zhang, P. Zhang, J. Yang, H. Liu, Bioresource Technology 99, 9029-9031 (2008)

2. Internet resources, www.huber.com.pl, 07.03.2012. 
3. M.S. Shehu, Z.A. Manan, S.R. Wan Alwi, Bioresource Technology 114, 69-74 (2012)

4. V.K. Tyagi, S-L. Lo, Rev. Environ. Sci. Biotechnol. 10, 215-242 (2011)

5. B.R. Dhar, G. Nakhla, M.B. Ray, Waste Management 32, 54 -549 (2012)

6. J. Abelleira, S.I. Pérez-Elvira, J. Sánchez-Oneto, J.R. Portela, E. Nebot, Conservation and Recycling 59, 52-57 (2012)

7. L. Appels., A. Van Assche, K. Willems., J. Degreve, J. Van Impe, R. Dewil, Bioresource Technology 102, 4124-4130 (2011) 